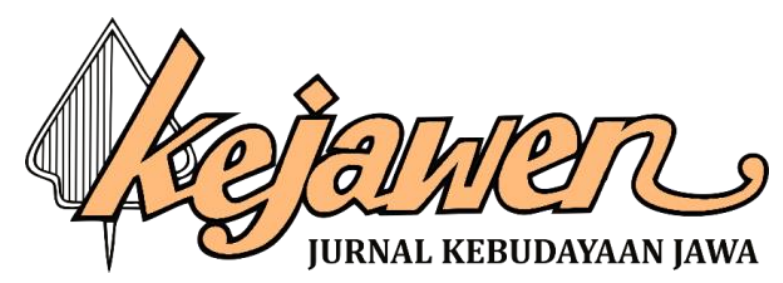

\title{
NILAI-NILAI ETIKA DAN ESTETIKA DALAM PROSESI UPACARA PERKAWINAN MASYARAKAT JAWA: WAHANA PEMBENTUKAN KARAKTER MULIA
}

\author{
Mulyana \\ Program Pascasarjana, Universitas Negeri Yogyakarta \\ mul_mj@yahoo.com
}

\begin{abstract}
Abstrak
Penelitian ini bertujuan untuk menjelaskan kandungan kultural dalam prosesi upacara perkawinan Jawa. Kandungan kultural yang paling mendasar adalah nilai etika dan estetikanya. Nilai etika berkaitan dengan proses dan muatan pembentukan karakter, moral, atau kepribadian orang menjadi lebih baik dan positif. Para pelaku prosesi harus mengikuti irama kedisiplinan dan karakteritik upacara pengantin Jawa. Irama prosesi dan substansi yang terkandung dalam prosesi itu sendiri menuntut tumbuhnya nilai-nilai positif etika, misalnya hormat, patuh, setia, disiplin, kerja keras, cekatan, pintar, dan tanggung jawab. Di samping pembentukan etika, prosesi ini juga menuntut dikembangkannya nilai-nilai estetika (bahasa, budaya, sosial). Pendekatan yang digunakan ialah sosiolinguistik, sosiokultural, dan dilengkapi dengan discourse analysis. Data yang digunakan berupa prosesi perkawinan Jawa dalam upacara perkawinan yang diselenggarakan oleh masyarakat Jawa di wilayah Yogyakarta. Hasil dari penelitian ialah; pertama, upacara perkawinan dapat membentuk sikap mental dan karakter yang mantap, diantaranya: disiplin, mandiri, ramah, berwibawa, dan bisa diteladani. Kedua, unsur-unsur estetika linguistik yang digunakan antara lain tembung saroja, tembung garba, yogyaswara, keratabasa, tembung entar, paribasan, bebasan, saloka, pepindhan, pralambang, purwakanthi, panambang ha-, seselan -in-, seselan-um-, tembung kawi, dan diksi religiusitas. Nilai-nilai estetika kultural dan sosial yang ditemukan antara lain nilai estetika dalam hubungan sosial, persaudaraan, dan anasir budaya Jawa (estetika rumah, busana, dan makanan). Nilai Etika dan estetika tersebut seiring dengan dinamika ekonomi, sosial, dan budaya masyarakat Jawa, yang menjadi konteks upacara perkawinan Jawa, mengalami dinamika dan perubahanperubahan yang lentur dan akomodatif. Namun perubahan itu tidak menghilangkan substansi utama pentingnya nilai budi pekerti luhur dalam budaya perkawinan adat Jawa.
\end{abstract}

Kata kunci: nilai etika, estetika, upacara perkawinan Jawa

\section{ETHICAL AND AESTHETIC VALUES IN THE JAVANESE MARRIAGE PROCESSION: A WAY FOR THE FORMATION OF NOBLE CHARACTERS}

\begin{abstract}
This study aims to explain the cultural content of the Javanese wedding ceremony procession. The most basic cultural content is its ethical and aesthetic values. Ethical values relate to the process and content of shaping people's character, morals, or personalities to be better and positive. The procession actors must follow the disciplinary rhythm and characteristics of the Javanese wedding ceremony. The rhythm of the procession and the substance contained in the procession itself demands the growth of positive ethical values, such as respect, obedience, loyalty, discipline, hard work, agility, intelligence, and responsibility. Apart from forming ethics, this procession also demands the development of aesthetic values (language, culture, social). The approach used is sociolinguistic, sociocultural, and is equipped with discourse analysis. The data used is in the form of Javanese wedding processions in wedding ceremonies held by Javanese people in the Yogyakarta region. The results of the
\end{abstract}


research are; first, the marriage ceremony can form a solid mental attitude and character, including discipline, independence, friendly, dignified, and can be exemplary. Second, the linguistic aesthetic elements used include tembung saroja, tembung garba, yogyaswara, keratabasa, tembung entar, paribasan, liberation, saloka, pepindhan, pralambang, purwakanthi, panambang ha-, seselan -in-, seselan -um-, Tembung Kawi, and the diction of religiosity. Cultural and social aesthetic values found include aesthetic values in social relations, brotherhood, and Javanese cultural elements (house aesthetics, clothing, and food). These ethical and aesthetic values are in line with the economic, social, and cultural dynamics of the Javanese people, which are the context for the Javanese wedding ceremony, experiencing flexible and accommodative dynamics and changes. However, this change did not eliminate the main substance of the importance of noble character values in the Javanese traditional marriage culture.

Keywords: ethical values, aesthetics, Javanese wedding ceremony

\section{PENDAHULUAN}

Masyarakat Jawa memiliki dan memelihara salah satu bentuk budaya adiluhung yang bersifat sosial dan kultural. Bentuk budaya itu diungkapkan dengan cara melakukan aktivitas verbal sosio-kultural berupa upacara-upacara atau prosesi tertentu yang langsung berkaitan dengan aktivitas kehidupan masyarakat itu sendiri. Salah satu bentuk prosesi budaya yang sangat penting dan mendasar bagi masyarakat Jawa adalah prosesi upacara perkawinan. Kajian tentang prosesi upacara perkawinan Jawa tidak saja berkaitan langsung dengan gejala estetika bahasa, melainkan juga berhubungan dengan masalah kepribadian, sosial dan budaya masyarakat pemiliknya. Artinya, semua aktivitas kultural yang berada dalam bingkai prosesi ini memiliki jangkauan aspek kehidupan manusia secara komprehensif yang penting.

Dalam hal nilai etika misalnya, prosesi perkawinan Jawa mampu mengantarkan personilpersonil atau pelaku prosesi untuk membina jati diri pribadinya agar lebih mantap dan berkarakter. Sejumlah hal yang dapat menjadi indicator terwujudnya nilai etika dan karakter seseorang adalah: pengucap piato diwajibkan memiliki kedisiplinan tinggi, menjaga perilaku, menjunjung tinggi sopan santun, menghormati orang lain, memuliakan masyarakat.

Di samping nilai etika-karakter, prosesi budaya ini juga menampakkan adanya nilai estetika dan susastra yang tinggi dan berkelas. Salah satu aspek yang tampak adalah penggunaan ragam bahasa Jawa krama yang halus, khas, sakral dan formal. Pemilihan ragam bahasa ini sangat mungkin berkaitan dengan pemakaian teks itu dalam sebuah acara seremonial resmi. Sebagaimana yang terjadi dalam masyarakat Jawa, pemakaian atau pemilihan ragam Krama pada umumnya terjadi apabila orang yang berbicara merasa perlu menghormati orang lain yang diajak berbicara. Upacara perkawinan, dapat dikatakan sebagai wahana komunikasi antar orang yang saling menghormati. Dalam situasi tersebut, sangat wajar apabila ragam bahasa yang digunakan bersifat formal.

Sementara itu, seorang pengucap pidato tidak akan menggunakan kata atau kalimatkalimat yang tidak runtut, atau asal bicara. Semua kalimat yang terucap diusahakan keluar dengan baik, runtut, dan saling berhubungan. Dalam pidato perkawinan, selalu ada keinginan atau kecenderungan orang yang berpidato dengan sempurna, dan dikagumi banyak orang. Pengucap pidato dituntut agar orang lain bersedia mendengarkan kalimat-kalimat yang keluar dari lisannya. Alasan utamanya ialah pidato mereka bersifat resmi, diperhatikan banyak orang, dan disampaikan dalam suasana keagungan sebuah upacara. Seorang pengucap pidato harus mampu menjadi teladan. Inilah sebuah wahana pembentukan karakter seorang pengucap pidato dalam upacara perkawinan adat Jawa.

Aristoteles, dalam bukunya yang berjudu Poetics juga menjelaskan bahwa sebuah karangan yang utuh, termasuk di dalamnya pidato, pada umumnya terdiri dari tiga bagian utama, 
yaitu bagian awal, tengah dan akhir (Syafe'ie, 1988:85). Bagian-bagian tersebut dihubungkan dan disatukan oleh berbagai aspek pengutuh wacana yang bersifat internal dan eksternal secara komprehensif. Aspek-aspek inilah yang sangat perlu dideskripsikan dan atau dijabarkan secara lengkap dan jelas untuk mendapatkan gambaran utuh tentang teks dan konteks prosesi pernikahan (PP) dalam bahasa Jawa secara lengkap. Kajian tentang PP dalam bahasa Jawa tidak saja berkaitan langsung dengan gejala bahasa, melainkan juga berhubungan dengan masalah kepribadian, sosial dan budaya masyarakat pemiliknya. Artinya, pelaku pidato sebenarnya tengah berada dalam bingkai pembangunan dan pembentukan karakter dan kepribadian yang mantap.

Sejumlah hal yang dapat menjadi indikator pembentukan jatidiri dan karakter ini antara lain adalah: pengucap pidato diwajibkan memiliki kedisiplinan tinggi, menjaga perilaku, menjunjung tinggi sopan santun, menghormati orang lain, memuliakan masyarakat. Oleh karena itu, kajian teks dan konteks tentang PP dalam bahasa Jawa diharapkan menghasilkan temuantemuan penelitian yang bermanfaat, baik dari segi kebahasaan (teks) maupun segi karakter (psikologis) dan sosio-kulturalnya (konteks). Upacara perkawinan, dapat dikatakan sebagai wahana komunikasi antarorang yang saling menghormati. Dalam situasi tersebut, sangat wajar apabila ragam bahasa yang digunakan bersifat formal. Keformalan itu pada gilirannya menjadi salah satu faktor terbentuknya teks PP menjadi sebuah wacana yang utuh dan lengkap.

Sementara itu, seorang pengucap pidato tidak akan menggunakan kata atau kalimat-kalimat yang tidak runtut, atau asal bicara. Semua kalimat yang terucap diusahakan keluar dengan baik, runtut, dan saling berhubungan. Dalam pidato perkawinan, selalu ada keinginan atau kecenderungan orang yang berpidato dengan sempurna, dan dikagumi banyak orang. Pengucap pidato dituntut agar orang lain bersedia mendengarkan kalimat-kalimat yang keluar dari lisannya. Alasan utamanya ialah pidato mereka bersifat resmi, diperhatikan banyak orang, dan disampaikan dalam suasana keagungan sebuah upacara. Seorang pengucap pidato harus mampu menjadi teladan. Inilah sebuah wahana pembentukan karakter seorang pengucap pidato dalam upacara perkawinan adat Jawa.

\section{METODE}

Data penelitian yang dikaji berbentuk lisan dan data tulis. Data lisan diperoleh dari tuturan langsung wacana pidato perkawinan yang dapat dijangkau dalam masa penelitian berlangsung. Data tulis diperoleh dari berbagai buku, majalah, koran, atau sumber tertulis lain yang memuat pidato perkawinan. Sumber tertulis tersebut antara lain adalah: (1) Sekar Setaman. Tatacara Upacara Perkawinan Adat Jawa (Kodiron, 1989), (2) Sekar Setaman (Suyadi, 1994), (3) Tuntunan kagem Para Panatacara tuwin Pamedharsabda (Yatmana, Rama Sudi. 1988), (4) Upacara Penganten Tatacara Kejawen (Sutawijaya, Danang. R. 1990), (5) Gita Wicara Jawi Pranatacara tuwin Pamedharsabda (Pringgawidagda, Suwarna, 1998). Sumber tersebut dipilih karena dianggap representatif.

Seting atau lokasi untuk melakukan penelitian ini adalah wilayah Daerah Istimewa Yogyakarta. Selanjutnya wilayah ini dijadikan sebagai populasi penelitian. Untuk mendapatkan data yang mewakili wilayah penelitian yang relatif luas tersebut, dilakukan pengambilan data dari kelima wilayah DIY tersebut, yatu Kota Yogyakarta, Kabupaten Sleman, Kulon Progo, Bantul, dan Gunung Kidul. Data diambil dari setiap wilayah tersebut dengan memperhitungkan aspekaspek: variasi budaya, kota-desa, model upacara, dan pelaku upacara. Situasi yang variatif ini diharapakan dapat terkumpul hasil data yang juga variatif dan representatif. Penyediaan data dilakukan dengan tiga langkah, yaitu: pengumpulan data, pencatatan data, dan penyeleksian data.

Pengumpulan data dilakukan dengan metode simak terhadap PP yang telah ditentukan sebagai sampel (Sudaryanto, 1991:24). Pada langkah ini tuturan teks PP disimak secara langsung (observasi) di lokasi berlangsungnya acara seremonial tersebut. Untuk menjaring dan mengumpulkan berbagai informasi yang penting, dilakukan wawancara dengan informan yang representatif. Informasi penting tersebut menyangkut berbagai hal, antara lain: gaya upacara 
perkawinan yang diselenggarakan, para pelaku pidato, sikap dan karakter pelaku pidato, asal calon pengantin pria, urut-urutan acara yang akan digelar, dan rancangan waktu acara.

Data yang telah tersedia kemudian dianalisis dengan tahap awal klasifikasi, yaitu: (1) memilahkan wacana PP berdasarkan jenis, (2) memilahkan wacana berdasar bentuk, pola estetika, dan konteks. Data yang telah berhasil diklasifikasi, kemudian dianalisis dengan teknik yang berkaitan dengan prinsip-prinsip analisis wacana. Sebagai sebuah gejala sosial, pidato dalam upacara perkawinan perlu dilihat berdasar hal-hal yang berkaitan dengan kemunculannya. Dengan kata lain, analisis data yang digunakan untuk mengurai pemakaian bahasa PP adalah metode kontekstual. Asumsi dan dasar pijakan utama analisis ini ialah menempatkan data selalu menyatu dengan konteks terjadinya tuturan. Teknik lain yang digunakan dalam analisis ini ialah teknikteknik analisis wacana (discourse analysis). Teknik ini digunakan untuk menjelaskan segala sesuatu yang menjadi faktor pengutuh PP, tujuan pemakaian wacana seremonial, keutuhan bentuk, karakter pelaku pidato, dan perubahan bentuk yang terjadi karena perbedaan konteks seremonial.

\section{HASIL DAN PEMBAHASAN}

Data penelitian dipilah dalam dua kategori analisis, namun keduanya kemudian dikonstruksi dalam satu kesatuan pemahaman komprehensif dan nintegralistik; kedua data tersebut adalah: (1) data linguistic (kebahasaan) dan (2) data nilai karakter. Analisis data kedua didasarkan pada analisis data pertama dengan dikonstruksikan dengan konteks budaya Jawa yang relevan. Data linguistic dianalisis untuk dikonstruksikan berdasarkan nilai estetikanya (keindahan), sementara data etika dikonstruksi dari konten yang ditemukan dalam pemakaian bahasanya. Berikut kedua nilai yang berhasil dikonstruksikan.

\section{Nilai Estetika Prosesi Perkawinan Jawa}

Berdasarkan kategori dan bukti linguistik yang berkembang dan digunakan dalam prosesi perkawinan Jawa, diketahui bahwa bahasa yang digunakan dalam upacara perkawinan Jawa dapat dimasukkan ke dalam kategori basa rinengga (bahasa yang dihias). Istilah basa rinengga mengacu pada nilai keindahan yang absolute dan formal, sehingga bersifat estetik. Beberapa aspek yang berhasil ditemukan sebagai argumentasi bahwa prosesi ini ini termasuk jenis prosesi ini yang indah (estetis) adalah adanya penggunaan aspek-aspek susastra Jawa. Sejumlah aspek penentu keindahan prosesi ini pidato dalam upacara perkawinan Jawa yang dapat ditemukan dalam kajian ini antara lain adalah penggunaan: 1) tembung saroja, 2) tembung garba, 3) yogyaswara, 4) keratabasa, 5) tembung entar, 6) paribasan, 7) bebasan, 8) saloka, 9) pepindhan, 10) pralambang, 11) purwakanthi (purwakanthi swara, purwakanthi sastra, purwakanthi lumaksita), 12) penambahan bunyi ha-, 13) seselan -in-, 14) seselan-um-, dan 15) tembung kawi. Penggunaan sarana estetika linguistic dalam prosesi tersebut tampak dalam tabel 2 berikut ini.

Tabel 1. Nilai Estetika-Linguistik dalam Prosesi Perkawinan Jawa

\begin{tabular}{|l|l|}
\hline Nilai Estetika prosesi & Aspek Estetika Linguistik \\
\hline Keseluruhan Prosesi & Ditemukannya unsur-unsur susastra Jawa: tembung \\
Verbal dan nonverbal & saroja, tembung garba, yogyaswara, keratabasa, \\
& tembung entar, paribasan, bebasan, saloka, \\
& $\begin{array}{l}\text { pepindhan, pralambang, purwakanthi, panambang } \\
\text { bunyi ha-, seselan -in-, seselan-um-, tembung kawi, } \\
\text { dan diksi religiusitas. }\end{array}$ \\
\hline
\end{tabular}

Tradisi pemakaian bahasa Jawa dapat dipilah menjadi dua, yaitu: (1) basa lumrah (biasa), (2) basa endah/rinengga (indah). Basa lumrah biasa digunakan dalam komunikasi sehari-hari, sementara basa endah digunakan dalam kesempatan formal, atau situasi seremonial dengan tujuan tertentu yang membutuhkan sentuhan estetika (Padmosoekotjo, 1959:10). Estetika atau keindahan 
suatu bahasa ditentukan oleh banyak hal; antara lain, pilihan kata (diksi), gaya bahasa, idiom, dan kata-kata khusus lainnya. Potensi estetika bahasa Jawa sebenarnya terletak pada kemampuan pemakai bahasa dalam memilih kata dan menggayakan kalimat ketika sedang berbicara atau menulis. Seorang peminat bahasa Jawa asal Australia yang bernama Jason Hawerdine menyatakan pengakuannya, "Basa Jawa iku endah lan adiluhung" (Bahasa Jawa itu indah dan tinggi). Selanjutnya, menurut Jason (Djaka Lodang, 2005:9), faktor-faktor penyebab keindahan bahasa Jawa terletak antara lain pada: (1) undha usuk (tingkat tutur), (2) produktivitas kosakatanya yang berlimpah, dan (3) banyak unsur susastra yang estetik dan beraneka ragam.

Produktivitas dan perbendaharaan kosa kata bahasa Jawa yang cukup berlimpah ditambah kosa kata lama (Kawi) yang bersifat literer, menjadi faktor utama mengapa bahasa Jawa mampu tampil dengan estetika formal di berbagai acara seremonial maupun dalam berbagai karya-karya di dunia fiksi. Artinya, ketika bahasa Jawa dituturkan secara wajar, biasa, dan bahkan kasar, maka estetika itu menjadi berkurang. Sebuah contoh, bahasa 'mempersilahkan makan' kepada para tamu dalam kesempatan resepsi perkawinan, akan tampil dalam bentuk yang berbeda jika dituturkan oleh seorang pranatacara profesional dengan pranatacara dadakan 'asal tunjuk'.

(1) Para tamu kakung saha putri sekaliyan, acara salajengipun inggih menika istirahat. Sasampunipun dipunaturaken dhaharan lan unjukanipun, kasuwun para tamu enggal ndhahar sasekecanipun.

Terjemahan:

Para tamu Bapak dan ibu sekalian, acara selanjutnya ialah istirahat. Sesudah disuguhkan makanan dan minuman, dimohon para tamu segera menikmati dengan seenaknya'

(2) Wonten ngarsanipun para tamu kakung saha putri ingkang sinuba ing pakurmatan. Dene adicara samangke badhe kasigeg sawetawis, ingkang saperlu para kadang pramuladi keparenga hangaturaken pasugatan ingkang awujud dhaharan saha unjukanipun. Keparengipun ingkang hamengku gati, panjenengan sekaliyan kersaa hangrahapi pasugatan menika kanthi merdikaning manah. Kadang juru pita swara kasuwun hangiringi sawetawis, sumangga.

Terjemahan:

'Kepada para tamu Bapak dan ibu yang pantas mendapat kehormatan. Adapun acara ini akan diistirahatkan sebentar, perlunya agar para sinoman mendapat kesempatan untuk menyediakan penghormatan berupa makanan dan minuman. Maksud yang punya keperluan, anda sekalian dimohon berkenan menikmati penghormatan ini dengan hati yang nyaman. Saudara petugas rekaman dimohon mengiringi (acara makan dengan lagu/musik), silahkan'.

Pada gaya (1) tampak pemakaian bahasa yang singkat, minim gaya, dan pemilihan kosa kata yang kurang hati-hati. Contoh, kata sasekecanipun 'seenaknya' ; kata ini bisa bermakna 'berbuatlah dengan sikap yang paling enak, bebas'. Konsep ini jelas kurang tepat untuk acara handrawina (menikmati makan) dalam budaya Jawa. Sementara pada gaya (2), digunakan pola kalimat yang lebih panjang, dihias-hias, dan pemilihan kosa kata yang lebih estetis. Misalnya, sinuba 'dipuja/disambut', hamengku gati 'punya hajat'. Ciri-ciri keindahan bahasa Jawa pada umumnya terwakili oleh gaya (2) di atas.

Contoh lain penggunaan sarana susastra Jawa yang estetik adalah digunakannya tembung Saroja. Tembung saroja adalah tembung loro kang padha tegese utawa meh padha tegese dienggo bebarengan 'dua kata yang bermakna sama atau hampir sama dipakai secara berturutan'. Pemakaian kata yang hampir sama tersebut sengaja digunakan untuk memperoleh makna 'lebih' 
dan bahasa yang 'indah' (estetis). Berikut penutup sebuah prosesi ini pasrah yang menggunakan pola tembung saroja.

(3) Kula sakulawarga ngaturaken pamuji sarta ing mugiya dhauping penganten kekalih tansah manggya sugeng rahayu widada nir hing sambekala.

Terjemahan:

'saya sekeluarga menyampaikan doa, serta harapan semoga perkawinan pengantin berdua selalu memperoleh keselamatan, terhindar dari kesulitan'.

Penggunaan pola tembung saroja terdapat pada kata sugeng rahayu widada. Ketiga kata itu sebenarnya memiliki arti yang sama, atau relatif sama, yaitu 'selamat sejahtera', namun sengaja digunakan secara bersamaan untuk memperoleh efek estetis dan tekanan makna yang mendalam.

Tembung saroja dalam prosesi ini biasanya merupakan bentuk dasanama 'sinonim'. Makna sinonim adalah kata lain yang memiliki makna yang relatif sama, tetapi digunakan secara bersama-sama. Jadi, estetika penggunaan tembung saroja terletak pada: (1) pola kesejajaran, (2) kata arkais yang digunakan sebagai sinonim, (3) variasi pemakaian kata dan (4) penekanan makna yang menyangatkan. Perhatikan beberapa contoh lain berikut ini.

(4) Dhumateng para lenggah sedaya ingkang kita mulyakaken. Nyuwun pangapunten wonten ing wekdal menika kula ingkang kadhapuk minangka dhuta saraya sulih sarira panjenenganipun Bapak Ahmad Jauhari saking Pisangan.

Terjemahan:

'Kepada para tamu yang kita muliakan. Mohon maaf saat ini saya yang ditugasi menjadi wakil/utusan Bapak Ahmad Jauhari dari Pisangan'

Kata yang bergaris bawah adalah tembung saroja. Kata dhuta berarti utusan, saraya juga bermakna sama, sementara sulih sarira juga berarti utusan atau wakil. Pemakaian deret sinonim itu digunakan untuk mendapatkan efek kata bermakna sama tetapi variatif. Penggalan prosesi ini itu akan menjadi kurang estetis atau paling tidak terkurangi keindahannya apabila hanya menggunakan satu kata saja, atau tidak memanfaatkan pola tembung saroja. Misalnya:

(4a) Kula ingkang kadhapuk minangka dhuta panjenenganipun Bapak Ahmad Jauhari saking Pisangan.

Atau, kurang indah apabila kata yang digunakan sebagai variasi sinonim bukan kata arkais, misalnya,

(4b) Kula ingkang kadhapuk minangka wakilipun panjenenganipun Bapak Ahmad Jauhari saking Pisangan.

Aspek atau nilai estetika tersebut dapat dikategorikan dalam piranti linguistic. Oleh karena itu nilai estetika dalam kajian ini lebih difokuskan pada estetika linguistic (kebahasaan). Namun, perlu dikatahui, bahwa estetika linguistic yang inheren terkandung terutama dalam prosesi verbal memungkinkan seseorang dan masyarakat pemilik budaya adiluhung ini untuk selalu mengaitkan dengan nilai rasa, perasaan, emosi, dan jiwa. Dengan demikian, etika dan estetika dalam prosesi ini benar-benar menjadi satu kesatuan bangunan yang saling mendukung.

\section{Nilai Etika sebagi Wahana Pembentukan Karakter Mulia}

Seorang pelaku pidato dalam upacara perkawinan memerlukan penyiapan sikap mental positif yang sangat penting dipupuk. Sikap dan karakter tersebut perlu dikembangkan untuk 
mendukung kewajibannya melaksanakan tugas menyampaikan pidato. Berikut hasil pengembangan sikap mental atau karakter setiap personal yang terlibat dalam upacara perkawinan Jawa.

(1) Pranatacara (master of ceremony):

Disiplin, tampil menarik, sikap menghormati orang, mampu mengibur orang, berkemampuan mengatur prosesi dan tamu, berbahasa yang runtut, baik dan indah.

(2) Pambagyaharja (tuan rumah):

Disiplin, sikap memuliakan tamu, berbahasa yang baik dan runtut.

(3) Pasrah-Tampi (orang yang menyerahkan dan menerima pengantin):

Disiplin, sikap memuliakan orang, rendah hati

(4) Sabdatama (orang yang memberi nasihat perkawinan):

Disiplin, sikap berwibawa dan berkarakter, bisa menjadi teladan

Para pelaku pidato tersebut sangat dibutuhkan oleh masyarakat Jawa dalam konteks keberlangsungan upacara perkawinan adat Jawa. Tidak dapat dibayangkan bagaimana jadinya, jika para personal penting tersebut sudah tidak ada lagi. Oleh karena itu, sikap mental dan karakter pengembangan diri harus dijaga dan dibangun sedemikian rupa untuk mendapatkan pribadipribadi yang berkarakter mantap dan dapat diteladani oleh masyarakat luas.

Tabel 2. Nilai Etika-Karakter dalam Prosesi Perkawinan Jawa

\begin{tabular}{|l|l|}
\hline \multicolumn{1}{|c|}{ Pelaku Pidato } & \multicolumn{1}{c|}{ Karakter / Sikap Mental } \\
\hline Pranatacara $(M C)$ & $\begin{array}{l}\text { Disiplin, tampil menarik, sikap menghormati orang, } \\
\text { mampu mengibur orang, berkemampuan mengatur } \\
\text { prosesi dan tamu, mampu berbahasa yang runtut, } \\
\text { baik dan indah }\end{array}$ \\
\hline Pambagyaharja & $\begin{array}{l}\text { Disiplin, sikap memuliakan tamu, berbahasa yang } \\
\text { baik dan runtut }\end{array}$ \\
\hline Pasrah-tampi & Disiplin, sikap memuliakan orang, rendah hati \\
\hline Sabdatama & $\begin{array}{l}\text { Disiplin, sikap berwibawa dan berkarakter, bisa } \\
\text { menjadi teladan }\end{array}$ \\
\hline
\end{tabular}

Intinya, nilai etika yang terwujud dalam pembentukan karakter atau kepribadian seseorang sangat nyata tampak pada eksistensi budaya Jawa dalam prosesi perkawinan. Namun, dalam kajian ini ditemukan juga adanya pergeseran dan perubahan nilai etika tersebut seiring dengan pergeseran jaman dan tuntutan masyarakat Jawa sendiri. Nilai-nilai etika tersebut pelan-pelan berubah dari substansi menjadi seremoni. Namun, substansi sebenarnya nilai etika tidak pernah berubah. Berikut nilai-nilai etika secara positif yang dapat diukur dan dimanfaatkan sebagai sarana pembungan masyarakat. Apabila sejumlah nilai tersebut bersatu dalam sebuah masyarakat, maka lahirlah nilai sosial bersama yang mampu membangun sendi-sendi kehidupan masyarakat secara bijak dan benar. Beberapa nilai etika yang terekpresi dalam data penelitian ini diantaranya adalah: nilai disiplin, nilai kesantunan komunikasi, dan nilai rendah hati sekaligus menghormati orang lain.

Nilai kedisiplinan sangat dibutuhkan orang yang ingin sukses. Tanpa itu, sangat jarang orang bisa mencapai kesuksesan. Para Mc dalam upacara perkawinan adat Jawa menjadi kunci keberhasilan upacara. Dia harus datang paling awal, untuk mengatur dan kalau perlu menjadwal ulang acara. Ketika tampil mengatur jalannya upacara, semua acara dan waktu harus dilaksanakan dan ditaati dengan ketat dan disiplin. Disinilah akan tumbuh nilai dan jiwa disiplin yang sangat dibutuhkan dalam kehidupan. Di samping MC, orang yang diberi tugas pidato lainnya juga harus menyesuaikan diri secara disiplin. Orang disiplin dan tegas dalam bertindak akan tampil sebagai manusia yang berwibawa dan berkarakter. 
Pada saat yang sama, seorang MC dalam upacara pengantin, juga sangat dituntut untuk selalu menghormati tamu dan semua orang yang hadir dalam resepsi tersebut. Caranya adalah dengan mengucapkan bahasa acara dengan ramah, indah dan tepat. Dia harus faham, siapa orang yang pantas didahulukan, siapa yang harus dipanggil, siapa yang harus dimohon duduk di tempat khusus, demikian seterusnya. Kemampuan inilah yang disebut nilai kesantunan berkomunikasi. Nilai ini juga dapat melatih orang hidup dengan damai di tengah masyarakatnya. Pada saat yang sama, MC dan pelaku pidato dalam upacara perkawinan adat Jawa, harus dapat menempatkan dirinya dengan sangat tepat, di hadapan semua orang yang hadir. Ia tidak perlu dengan bangga menjelaskan dirinya, prestasinya, keterkenalannya. Lebih dari itu, penampilannya seyogyanya tidak boleh lebih glamor dibanding pengantinnya. Nilai kerendahan hati ini mendidik manusia agar lebih paham dimana dan bagaimana dirinya harus menempatkan posisinya di tengah masyarakat nyata. Jadi, nilai-nilai etika dan estetika dalam bahasa Jawa tersebut, bila dipahami dengan baik dan tepat, mampu membangun manusia secara utuh dan berbudi. Orang atau masyarakat yang mengerti dan mampu memanfaatkan nilai-nilai etika dan estetika akan lahir sebagai manusia yang berbudi luhur, mampu beradaptasi sosial dengan tepat (manjing ajur ajer), memilih bahasa dan cara komunikasi dengan halus dan tepat (bener lan pener), bahkan pada puncaknya manusia seperti inilah yang mampu membangun komunitas dan masyarakatnya menjadi lebih berbudi, santun dan penuh kedamaian.

\section{SIMPULAN}

Berdasarkan uraian dalam pembahasan di depan, berikut ini disajikan sejumlah kesimpulan yang diharapkan dapat menjadi bahan pemahaman akhir tentang fokus kajian ini. Prosesi ini mampu membina karakter seseorang (pelaku prosesi) untuk memantapkan kepribadiannya menjadi lebih mantap dan disiplin. Pidato dalam upacara perkawinan membutuhkan para personal (pelaku pidato) dengan sikap mental dan karakter yang positif dan mantap. Mereka yang telah diberi amanat untuk melaksanakan tugas pidato terkondisikan untuk menyiapkan sikap mental dan karakter yang sesuai dengan jejibahan-nya (kewajibannya). Oleh karena itu, wahana ini dapat dijadikan momentum bagi pengembangan karakter seseorang. Meskipun, bahasa yang digunakan kadang-kadang bercampur antarbahasa, namun unsur-unsur estetika prosesi ini (indah, literer, dan arkais) akan tetap dipertahankan. Tujuan pemertahanan bahasa Jawa dengan nilai etik dan estetik adalah, terbentuknya sistem kebaikan bersama yang dapat disepakati bersama sebagai nilai sosial adiluhung masyarakat. Dari sinilah dapat diharapkan tumbuhnya masyarakat yang nyaman, damai dan sejahtera.

\section{DAFTAR PUSTAKA}

Atmojo. (1991). Sekar Pahargyan Pengantin. Yogyakarta: Media Pustaka.

Bratawidjaja, Thomas Wijasa. (1995). Upacara Perkawinan Adat Jawa. Jakarta: Pustaka Sinar Harapan.

Halliday. MAK. (1978). Language as Social Semiotics. USA: Edward Arnold.

Halliday, MAK dan Ruqaiya Hassan. (1992). Bahasa, Konteks dan Teks. Aspek-aspek Bahasa dalam Pandangan Semiotik Sosial. Yogyakarta: Gadjah Mada University Press.

Kadarisman, A. Effendi. (1999). Wedding Naratives as Verbal Art Performance: Explorations in Javanese Poetics. Disertasi. Universitas of Hawaii.

Kodiron. (1989). Sekar Setaman. Tatacara Upacara Adat Jawa. Surakarta: Putra Angkasa.

Longacre, Robert E. (1968). Discourse, Paragraph, and Sentence Structure in Selected Philippine Languages. Santa Ana California: The Summer Institute of Linguistics.

Mulyana. (2001). "Penggunaan Unsur Kohesi dan Koherensi dalam Naskah Sesorah Bahasa Jawa”. Laporan Kajian. Yogyakarta: Lembaga Kajian Universitas Negeri Yogyakarta.

Pringgawidagda, Suwarna. (1998). Gita Wicara Jawi Pranatacara tuwin Pamedharsabda. Yogyakarta: Kanisius. 
Respationo, Suyadi. (1994). Upacara Mantu Gagrag Surakarta. Semarang: Dahara Prize.

Sutawijaya, Danang. R. (1990). Upacara Penganten Tatacara Kejawen. Semarang: Aneka Ilmu. Suwarna. (2003). "Estetika Bahasa Pembawa Acara Pengantin Jawa”, Laporan Kajian FBS UNY. Suyadi, R. (1994). Sekar Setaman. Yogyakarta: CV Cendrawasih.

Yatmana, Rama Sudi. (1988). Tuntunan Kagem Para Panatacara tuwin Pamedharsabda. Semarang: Aneka Ilmu. 